\title{
RESEARCH
}

\section{A note on Factors Affecting the Effectiveness of Technical Assistance}

\author{
by Alistair MacBean and Kathryn Morton ${ }^{1}$
}

The purpose of the Lancaster study ${ }^{2}$ is to attempt an appraisal of some of the factors which determine the efficiency of technical assistance programmes. It is hoped that it will provide guidelines to ways of improving project selection, implementation and evaluation. Apart from the study of existing published material and documentation the project involves enquiries by questionnaire and interview aimed at donor agencies, host governments and their agencies, and personnel who have been engaged during the past 5 years as technical assistance experts in developing countries. So far a survey of personnel who have been on missions under the British programmes ${ }^{3}$ of technical assistance has been completed as well as interviews with officials of the governments of Kenya and Tunisia and of donor agencies operating in these countries. This brief note on progress concentrates on some of the results from the survey and the problems of interpretation which inevitably accompany the use of sample survey techniques. The first phase of this project has as yet been confined to British technical assistants returning from service. In later phases, it will include French and U.N.D.P. persornel.

\section{Methodology}

The sample of approximately 500 was randomly selected from about 1,000 technical assistance experts listed by the Ministry of Overseas Development as having returmed from their assignments between January 1967 and September 1969. Each of the 497 experts selected was sent a copy of a questionnaire developed from a brief test in a small pilot study, as well as comments from those experienced in survey design. The pilot study had revealed no significant difference between questionnaires which we completed

1 A. I. MacBean is Prof essor of Economics at the University of Lancaster, and Kathryn Morton is a Research Assistant.

2

A study on the evaluation of technical assistance which is financed by a research grant from the Social Science Research Council.

3 Excluding the operational T。A. personnel under O.S.A.S. and B.E.S.S. 
36.

on the basis of a $1 \frac{1}{2}$ to 2 hour interview and ones filled in and returned by post. The results of the pilot study gave grounds for aiming at a wider coverage and avoidance of interviewer bias by adopting a postal survey technique as against the interview method. The final amended questionnaire was sent with a covering letter assuring recipients of confidentiality and the eventual response was 342 , almost 70 per cent of the sample.

We obtained certain basic information on both respondents and non-respondents: sex, age, marital status, location, length and approximate nature of their assignment and the date of their return. From among these variables the only one which emerges as significant is the expert's date of return. Those more recently returned were more likely to reply to the questionnaire.

A more significant potential source of bias through nonresponse is that the nature of the expert's experience and/or his attitudes to his assignment may have influenced his willingness to reply. For example, it may be that those who felt that their mission was successful would be keen to talk about it. Alternatively, the malcontent or the hypercritical may also be the ones most anxious to set down their impressions. On the whole from such evidence, and from external checks and built-in checks in the questionnaire, it seems to us unlikely that any serious biases are likely to have resulted from the failure to obtain replies from some 30 per cent of the initial sample.

The results recorded below are some of the preliminary findings from the survey. They are to be treated with caution and are put forward for discussion and comment rather than for quotation at this stage. What follows gives a broad picture.

\section{Preliminary Findings}

In the transfer of skills via T.A., a number of problems arise as a result of the nature of process itself and its present organization. In consequence the efficiency with which T.A. resources are utilised may be hampered. The very fact that human beings are the agents of transfer immediately creates the need for adjustment. The individual expert has to cope with a radical change in his environment and with an unfamiliar work situation. The expert moreover tends to be employed on a short-term basis and the lack of normal incentives may affect his performance not all are altruists. A further problem which may reduce the experts' effectiveness is that counterpart personnel and trainees are often not provided as expected. Likewise the absence of adequate working facilities may limit the expert. Donors, recipients and the expert himself have a role to play in removing or reducing these problems where they arise.

The speed and ease with which the expert adapts to the change of job and environment and thus becomes potentially effective is dependent on a number of factors. The expert himself is a key variable. 
It can be argued that loss of efficiency through adjustment can be reduced if the experience gained by individual experts is used, not only through evaluation exercises but also by employing the same person for more than one assignment. The British T.A. programe provides a career for only a few: the majority of the respondents were employed on a short-term basis only. Nevertheless a large number - two-thirds - had had previous working experience in a developing country, and a considerable number of those on shorter tours had had more than one experience of this kind. Although only two-fifths had worked under a T.A. programme before and only one-fifth in the same country before, their work had generally been similar to that of their ToA。 assignment。 The majority felt this experience to be of value to their T.A. work. As a group, they appear to be more tolerant, or to find things easier, than those without previous experience. They were also less likely to require outside help in their domestic affairs or in the implementation of their assignment.

Age is often mentioned as an important factor in determining the local acceptance of an expert and hence his success. It has been said that the older expert is at an advantage in societies where seniority gains automatic respect. However the ideal age of a T.A. expert remains a moot point and not susceptible to generalisation. In our survey the average age of respondents was 49 - few were under 35 and a few were over 65. Our analysis to date has not revealed any significant differences in performance which could be attributable solely to age.

\section{Briefing and Language}

Advance preparation for a ToA. assignment seems clearly to aid adjustment. Since, in fact, relatively few British experts venture into wholly non-English speaking regions, language is seldom a serious problem. Nevertheless $9 \%$ of our sample considered knowledge of a foreign language to be essential and a further $30 \%$ thought it would have been useful. Less than a third of the former group had adequate fluency on arrival, the majority acquired it while on tour, while a few did not. In the latter group, the majority did not acquire sufficient knowledge before or during their assignment. There is no doubt that the majority of those experts who thought that to know the language was essential and who had to learn it while on tour were hampered by their lack of knowledge. Fellow team members and interpreters, where they existed, provided a less than satisfactory solution.

With respect to briefing, respondents were asked to state whether they were officially briefed on each of the following topics: the job, the domestic details, the socio-economic background of the country, and T.A. in general, and to comment on 
38.

whether they found it adequate or not. Roughly one-third of the sample were either not briefed or found their briefing inadequate. Only a small proportion were not briefed and considered unnecessary. Job briefing was the most frequently received and the most of ten considered inadequate. There is a significant correlation between those finding job briefing inadequate and those finding a divergence between the job description and the actual job. This suggests a lack of care in investigation at the project selection stage as well as in the preparation of the expert. The survey supports the view that briefing is better given on arrival: information is likely to be more up-to-date and accurate and the expert more receptive. Nevertheless, only a minority of respondents were briefed by British officials abroad.

\section{$\underline{\text { Reports }}$}

Throughout implementation both the donor and the recipient agencies have a role to play in ensuring that the expert can work efficiently. Support from donor agency officials during the expert's assignment can help to reduce difficulties which may arise and can aid morale. A regular system of reporting can provide a means of locating problems and checking on progress, while at the same time providing a performance incentive for the expert and a store of information for future projects.

Less than $20 \%$ of the respondents made formal reports to officials in the country of their assignment and less than half, including the majority of the former group, made reports to ODM during their assignment. Roughly a third of all experts had no contact of any kind with ODM during their assignment - not all of whom were on short tours. The majority of respondents had meetings with British officials abroad, but nearly a fifth felt that they had insufficient contact of this kind. This group tended to be on longer tours and had had no previous working experience in developing countries.

Help on specific matters relating to the expert's work raises a problem of the extent to which British officials can intervene without being accused of undue interference. A few respondents recognised this to be a limitation and had consequently not sought assistance. Others had not considered the Embassy capable of providing help. $\quad 37 \%$ experts had required assistance at some stage in their assignment. But just over half considered the help received effective while nearly a third thought it ineffective and $11 \%$ received none. The former group were the respondents most likely to consider their assignment to have been successful, the latter the least likely.

\section{Local Facilities}

On the recipient side, provision of adequate personal domestic and work facilities and efforts to create an environment in which the expert can function effectively can clearly affect his 
performance and the success of his assignment. Respondents were asked to state whether they found facilities satisfactory and whether they considered the host organization efficient. The majority found facilities wholly or partially satisfactory, $44 \%$ an $34 \%$ respectively. Roughly $20 \%$ found them partially or wholly unsatisfactory. With respect to efficiency, again the majority considered the host organization to be efficient (27\%) or fairly efficient $(34 \%)$. A third thought it rather or wholly inefficient.

\section{Training}

The greatest source of discontent amongst respondents arose from problems relating to training of local personnel. Just over $60 \%$ of respondents had some training function in their assignment. The most serious problems were felt to be the lack of time made available for training purposes, the poor calibre of the local personnel involved, and their paucity. Over half of the respondents who had trainees and/or counterparts considered that the time available was insufficient for adequate training, and that their calibre was too low。

\section{Conclusion}

This summary of our preliminary findings has of necessity been brief and rather tentative. Nevertheless it suggests some conclusions. Firstly, while the ad hoc character of British T.A. does militate against the creation of a stock of experienced career personnel, in fact over two-thirds of our sample had previous experience in a developing economy and two-fifths had worked in T.A. before. Secondly, while the majority of the experts appear satisfied with their briefing a very large minority are not, and language training was felt to be inadequate. Thirdly, support in the field seems to have been unsatisfactory or totally lacking in quite a large number of cases. The complaints about the lack of or quality of trainees and counterparts mertioned by all T.A. donors are echoed by the majority of the T.A. experts in our study. Clearly there is still considerable room for improvement in the British programme of technical assistance to developing countries. 